\section{Negatividad de la subjetividad y esperanza en la antropología teológica de Juan Alfaro*}

\author{
Carlos Ábrigo ${ }^{a}$ \\ Universidad Católica Silva Henríquez, Chile \\ http:/ / orcid.org/0000-0003-3547-4938
}

Resumen: En la antropología teológica de Juan Alfaro, S. J. (1914-1993), la subjetividad (conciencia y libertad) constituye la dimensión humana donde coexisten aspectos de positividad y negatividad. En la negatividad el hombre vive la experiencia de amenaza del sinsentido de su existencia por el hecho de nunca estar en posesión plena de sí, pero fundamentalmente por la experiencia de la muerte. Esta negatividad, sin embargo, es la dimensión existencial desde donde emerge la actitud de rebelión contra tales amenazas y se incita el don de la esperanza. Para la expresión de estos contenidos, el autor señala que las categorías esencialistas orientadas a demostrar deben dar lugar a categorías personalistas orientadas a mostrar, desafío aún pendiente según lo que expresa el papa Francisco.

Palabras Clave: Antropología teológica; Juan Alfaro; subjetividad; conciencia; libertad; muerte; sinsentido; esperanza.
Negativity of Subjectivity and Hope in the Theological Anthropology of Juan Alfaro

AвsтrACt: In the theological anthropology of Juan Alfaro, S. J. (1914-1993), subjectivity (consciousness and freedom) constitutes the human dimension where aspects of positivity and negativity coexist. In negativity, man experiences the threat of the nonsense of his existence because he is never in full possession of himself, but mainly because of the experience of death. This negativity, however, is the existential dimension from which the attitude of rebellion against such threats emerges and the gift of hope is incited. For the expression of these contents, the author points out that the essentialist categories oriented to demonstrate must give place to personalist categories oriented to show, a challenge still pending according to what Pope Francis expresses.

KeYwords: Theological anthropology; Juan Alfaro; subjectivity; awareness; freedom; death; nonsense; hope.

\section{Cómo CITAR:}

Ábrigo, Carlos. "Negatividad de la subjetividad y esperanza en la antropología teológica de Juan Alfaro, S. J.”. Theologica Xaveriana 187 (2019): 1-25. https:// doi.org/10.11144/javeriana.tx69-187. nseatj

\footnotetext{
*Artículo de reflexión.

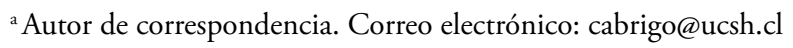




\section{Introducción}

Para Alfaro, la conciencia constituye la dimensión fundamental de la existencia humana a partir de la cual el hombre, de modo inmediato, es capaz de vivir la experiencia de estar ante la realidad de su propio ser espiritual. De ahí que esta conciencia -entendida como autopresencia vivida del propio yo, es decir, como sujeto personal en su peculiaridad indecible ${ }^{1}$ - sea el principio básico donde se asienta la absoluta originalidad de la existencia humana ${ }^{2}$, como también su dignidad ${ }^{3}$ y superioridad respecto de la naturaleza ${ }^{4}$, por el hecho de tener su origen en Dios. En este sentido, la conciencia se manifiesta como realidad esencialmente positiva y diversa respecto a las realidades del mundos.

En efecto, después de un largo y complejo proceso reflexivo relacionado con el carácter natural o sobrenatural del ser personal del hombre ${ }^{6}$, Alfaro llega al convencimiento de que los procesos naturales por sí mismos son insuficientes para explicar el origen de la conciencia y de la libertad como constitutivos del ser personal del hombre, debido a que ambas "trascienden el funcionamiento neuronal del cerebro humano"7 A partir de esto concluye que en el proceso evolutivo natural de la materia debió intervenir un "plus"8 procedente de Dios, como realidad trascendente y personal que -al otorgar conciencia y libertad al mundo a través del hombre- funda el ser personal de este'. Con ello se inaugura el paso de un devenir cósmico predecible a un devenir histórico impredecible, en el que el mundo queda abierto a un ilimitado porvenir.

\footnotetext{
${ }^{1}$ Para Alfaro, la subjetividad (conciencia y libertad) constituye la dimensión de convergencia participativa entre Dios y el hombre, que se erige como el fundamento de su ser personal a imagen de aquel. Véase a Ábrigo, "El origen divino de la subjetividad en la reflexión teológica de Juan Alfaro. Las repercusiones en el hombre y las tensiones intelectuales del autor presentes en este proceso".
}

${ }^{2}$ Alfaro, Esperanza cristiana y liberación del hombre, 16; ídem, "Las esperanzas intramundanas y la esperanza cristiana", 352-353; ídem, "La cuestión del sentido y el sentido de la cuestión", 389; ídem, "La cuestión del hombre en su relación al mundo", 211.

3 Ídem, "La negación nihilista del sentido de la vida: Nietzsche y Sartre", 99.

${ }^{4}$ Ídem, "La antropología de Karl Marx”, 179.

5 Ídem, "La negación nihilista del sentido de la vida: Nietzsche y Sartre", 97; ídem, "Las esperanzas intramundanas y la esperanza cristiana", 352-353; ídem, "La cuestión del hombre en su relación al mundo", 211.

${ }^{6}$ Ábrigo, "El origen divino de la subjetividad en la reflexión teológica de Juan Alfaro. Las repercusiones en el hombre y las tensiones intelectuales del autor presentes en este proceso", 97-104.

${ }^{7}$ Alfaro, "La cuestión del hombre en su relación al mundo", 212, Nota 12.

8 Ídem, "El hombre abierto a la revelación de Dios", 30; ídem, "La cuestión del hombre en su relación al mundo", 216.

${ }^{9}$ Ibíd. 
A las ilimitadas potencialidades objetivas de la naturaleza corresponde la ilimitada proyectiva del hombre. Y viceversa: a la posibilidad ilimitada de crear lo nuevo, propia del hombre, corresponde la posibilidad ilimitada de la naturaleza de ser transformada.

Esta correspondencia mutua entre el hombre y la naturaleza permite comprender al hombre como momento culminante del devenir cósmico, que precisamente en el hombre da el paso definitivo hacia la realidad nueva del devenir histórico: dando origen al hombre, la evolución se ha lanzado más allá de sí misma hacia una órbita más elevada, hacia un futuro siempre nuevo. Se puede decir, pues, que el devenir cósmico alcanza su sentido en el hombre, en cuanto logra en él su configuración suprema, que a su vez confiere al mundo la apertura a un futuro sin límites. ${ }^{10}$

A pesar de la positividad esencial de la conciencia, para el teólogo español, ella también constituye esa dimensión donde, simultáneamente, el hombre se encuentra con la experiencia inmediata de su no ser, su finitud, su angustia, lo cual manifiesta que junto a su esencial positividad convive un ámbito de negatividad ${ }^{11}$.

Esto lo lleva, consecuentemente, a afirmar que la indivisible conciencia del propio ser existente en el hombre (su autopresencia espiritual), unida a los condicionamientos propios que le comporta su finitud, constituyen la base que fundamenta su radical inquietud, su esencial tensión en la orientación que posee hacia la plenitud ${ }^{12}$. Esta tensión, no obstante, viene a ser la experiencia que da lugar a la inserción de la llamada que realiza la gracia a la esperanza de salvación para él y para la historia ${ }^{13}$.

Como puede apreciarse, la positividad de la subjetividad -asociada a su rica reflexión teológica acerca de la gracia- es la característica principal de la antropología de Alfaro; pero, por ser él un teólogo que se ubica en la corriente teológica de la posguerra, adoptará (considerando además la crisis de las categorías asociadas a filosofías de talante esencialista) la fenomenología existencial como punto de arranque para la reflexión trascendental.

Este hecho le permitirá entrar en diálogo con el pensamiento de Heidegger y de Sartre, entre otros que influirán decisivamente en su reflexión hamartológica asociada

${ }^{10}$ Ibíd., 21; también 23 y 28; 47-48; ídem, "La cuestión del hombre en su relación al mundo", 204; ídem, "El devenir histórico y su sentido", 257-258.

${ }^{11}$ Ídem, "Las esperanzas intramundanas y la esperanza cristiana", 352-353; ídem, "La dimensión trascendental en el conocimiento humano de Dios según Santo Tomás", 673; ídem, "La cuestión del hombre y de Dios en la filosofía de I. Kant, L. Feuerbach y M. Heidegger”, 52; 56; 61-62; 66-67; ídem, "La negación nihilista del sentido de la vida: Nietzsche y Sartre", 97; 104-105.

12 Ídem, "Las esperanzas intramundanas y la esperanza cristiana”, 352-353; ídem, "La cuestión del sentido y el sentido de la cuestión", 389.

${ }^{13}$ Ídem, Esperanza cristiana y liberación del hombre, 31-32. 
a una subjetividad permanentemente acosada por la experiencia del sin sentido de la vida, del absurdo existencial, de la angustia (primera parte del presente artículo); acosada, en definitiva, por la misma muerte, como experiencia anticipada en el devenir de la existencia y como la expresión más radical de la negatividad de la subjetividad. Este tema será tratado en la segunda parte de este artículo.

Ahora bien, la mencionada crisis de las categorías esencialistas, que conlleva la adopción de la fenomenología existencial por parte de Alfaro, le darán la base hermenéutica, centrada en el sujeto, desde la cual penetrará en el tema propio del presente artículo. En efecto, dan cuenta de ello la distinción que hace entre conocimiento temático (equivalente a certeza refleja) y conocimiento atemático (equivalente a certeza vivida, no categorial), así como la que realiza entre demostración y mostración.

Esto, claramente, es coherente con su actitud crítica -expresada ya en la década de los años cincuenta- hacia el lenguaje análogo y en favor de la intuición como medio para referirse, por ejemplo, a la relación entre lo natural y lo sobrenatural, entre el hombre y Dios ${ }^{14}$. Posteriormente esta actitud quedará corroborada mediante la búsqueda de nuevos instrumentos hermenéuticos centrados en la subjetividad, lo que se plasmará en un artículo publicado en 1960, donde aborda las mismas problemáticas a partir de categorías personalistas ${ }^{15}$.

En la conclusión mostraremos que esta preocupación de Alfaro (negatividad de la subjetividad, esperanza y apertura a nuevas formas de lenguaje) sigue vigente en la actualidad, y constituye una inquietud importante para el papa Francisco.

\section{La negatividad de la subjetividad en relación} con la cuestión del sentido de la existencia humana, la esperanza, y la cuestión de Dios

\section{La conciencia, dimensión-sede de la experiencia de autopresencia incompleta y de la consecuente amenaza de fracaso existencial}

Si bien el hombre puede vivir la experiencia de estar ante la realidad de su ser en el seno de su propia conciencia, se trata siempre de una autopresencia incompleta -identidad no plena-, pues en tal experiencia nunca alcanza a coincidir plenamente consigo mismo, es decir, no llega a lograr conciencia pura de sí. Para Alfaro, ello

${ }^{14}$ Ídem, "Trascendencia e inmanencia de lo sobrenatural”, 10; 15-16; 32; ídem, "Cristo glorioso, revelador del Padre”, 247-248; ibíd., 266.

${ }^{15}$ Ídem, "Persona y gracia”, 5-29. 
manifiesta la necesidad permanente de contraponer su subjetividad -por medio del pensar, el querer o el hacer- con la dimensión objetiva de la realidad (con lo que no es él mismo), para alcanzar presencia de $s^{1}{ }^{16}$.

Desde esta perspectiva, la coincidencia plena señalada se presenta más bien como un llamado y desafío a ser más sí mismo, a ir haciéndose mediante la vinculación dinámica y constante con lo otro -el mundo- y con los otros sujetos ${ }^{17}$. En ese afán, el hombre vive la permanente experiencia, imposible de suprimir, del desnivel existente entre la limitación propia de su ser y actuar y su aspiración ilimitada -entendida como condición previa de todo su progreso en el mundo-, en orden a una realización que siempre lleva el sello de la ulterioridad, de la penultimidad de toda meta alcanzada; en definitiva, de una plenitud imposible de alcanzar por sí mismo ${ }^{18}$.

Esta situación (ser sí mismo sin poder nunca plenamente serlo, como expresión de una incurable escisión interior entre la aspiración sin límites de la subjetividad vivida y las expresiones que de ella emergen, nunca definitivamente objetivadas ${ }^{19}$ hay que entenderla, de acuerdo con lo indicado, como experiencia existencial primera y básica de insuperable inquietud radical -anidada en la autoconciencia-, que pone en evidencia la paradoja constitutiva del hombre, por la cual este se erige en cuestión ineludible para sí mismo ${ }^{20}$.

Queda así de manifiesto -según Alfaro- que la conciencia se erige como la dimensión donde se anida la aspiración apriórica del hombre a ser él mismo en su singularidad incomunicable; como el espacio interior donde se arraiga su anhelo a permanecer como tal, incluso en medio de las continuas e irreversibles acciones que ejecuta libremente en el mundo ${ }^{21}$. Sin embargo, por causa de la fragilidad de su libertad,

${ }^{16}$ Ídem, Hacia una teologia del progreso humano, 39; ídem, Esperanza cristiana y liberación del hombre, 17; 27; ídem, "Las esperanzas intramundanas y la esperanza cristiana", 352; ídem, "La cuestión del sentido y el sentido de la cuestión", 388-389; ídem, "El hombre abierto a la revelación de Dios", 41; ídem, "La negación nihilista del sentido de la vida: Nietzsche y Sartre", 97; ídem, "Epílogo", 278.

${ }^{17}$ Ídem, "La cuestión del sentido y el sentido de la cuestión", 388-389. En este punto, Alfaro tiene como referencia el pensamiento de Sartre, particularmente lo que el autor francés entiende por para si. Al respecto véase a Alfaro, "La negación nihilista del sentido de la vida: Nietzsche y Sartre", 96-97.

${ }^{18}$ Ídem, Esperanza cristiana y liberación del hombre, 18-19; 27; 202; ídem, "La cuestión del sentido y el sentido de la cuestión", 389; ídem, "El hombre abierto a la revelación de Dios", 14; 23-24; 52; ídem, "Las esperanzas intramundanas y la esperanza cristiana", 353; ídem, "La negación nihilista del sentido de la vida: Nietzsche y Sartre, 97-98; ídem, "La muerte y el sentido de la vida", 251; ídem, "El devenir histórico y su sentido", 264.

${ }^{19}$ Ídem, "Esperanza marxista y esperanza cristiana”, 105.

${ }^{20}$ Ídem, "La cuestión del sentido y el sentido de la cuestión", 389; ídem, "El hombre abierto a la revelación de Dios”, 14; ídem, "Epílogo”, 278.

${ }^{21}$ Ídem, Esperanza cristiana y liberación del hombre, 17-18; 23; ídem, "Las esperanzas intramundanas y la esperanza cristiana”, 352-353. 
sobrepasada absolutamente por el futuro trascendente al cual se orienta, el hombre nunca está en posesión de la certeza de su propia realización, lo cual conlleva -precisa Alfaro- un riesgo inevitable para él: la posibilidad de su fracaso existencial ${ }^{22}$, originada por la presencia del pecado en él, como anticipo de perdición ${ }^{23}$.

Tal fracaso, en concreto, se verificaría en el caso de que la conciencia -acosada por dicho riesgo y dejándose mover por los impulsos egocéntricos y autosuficientes instalados en el hombre- oriente a su libertad a sucumbir ante la tentación de optar por el rechazo de la trascendencia de Dios, de su propia trascendencia respecto del mundo, y/o de la dimensión comunitaria de su existencia. En tal situación, sus acciones en relación con el progreso de la historia quedarían reducidas a un dinamismo cuyo curso se desarrollaría solo al interior de un horizonte estrictamente mundano, en búsqueda de una plenitud puramente inmanente, para negar con ello la dimensión trascendente que dichas acciones pudieran tener sobre el mundo.

Así, la posibilidad que tiene la libertad de responder con un sí a la misteriosa interpelación de Dios lleva implícito inevitablemente el riesgo dramático de optar por el $n o^{24}$, y con ello, la posibilidad cierta de absolutizar la relación del hombre con el mundo, privando a esta relación de toda dimensión trascendente.

En este sentido, para Alfaro existen determinadas estructuras sociales que encarnan dicha reducción inmanente del devenir histórico, en virtud de lo cual se convierten en fuentes permanentes que inducen a los hombres al pecado:

La expresión humana del pecado tiende a objetivarse en estructuras sociales, que pertenecen al "pecado del mundo" (el mundo enemigo de Dios) e inducen a la humanidad a la negación de Dios. Como acción del hombre en el mundo y sobre el mundo, el pecado niega la ordenación del mundo a Dios a través del hombre y de este modo pone al mundo en contradicción consigo mismo, con el hombre y con Dios. ${ }^{25}$

\section{La esperanza anidada en la subjetividad del hombre como fundamento de un porvenir de gracia}

A pesar de lo señalado, Alfaro considera que las mencionadas expresiones de la negatividad de la conciencia se alzan como llamado a la esperanza, entendida esta como dimensión trascendental que también habita en la subjetividad, cuya respuesta

\footnotetext{
${ }^{22}$ Ídem, Esperanza cristiana y liberación del hombre, 18; ídem, "Las esperanzas intramundanas y la esperanza cristiana", 352-353; ídem, "Epílogo", 278.

${ }^{23}$ Ídem, Esperanza cristiana y liberación del hombre, 18.

${ }^{24}$ Ídem, Hacia una teología del progreso humano, 29-30; 60-61.

${ }^{25}$ Ibíd., 61.
} 
consiste en un lanzamiento confiado del creyente hacia el futuro ${ }^{26}$, basada en la certeza de sentido que otorga la experiencia de vivir dicha esperanza ${ }^{27}$.

En efecto, esta certeza de sentido conmina al hombre a renunciar radicalmente a toda pretensión autosuficiente que tienda a salvarse por sí mismo a través de sus obras, y a abandonarse en cambio al amor de Dios como garantía única de salvación y como reconocimiento vivido, no categorizado, de la impotencia humana en orden a su propia salvación ${ }^{28}$.

En este sentido, la esperanza, en cuanto permanente llamado a la libertad para la toma de una decisión, evita que esta quede paralizada, y se constituye en la dimensión trascendental -esperanza trascendental esperante- que, desde lo más profundo del espíritu finito, impulsa al hombre a asomarse a un porvenir cuya consecución le es imposible alcanzar por sus propios medios y que, en consecuencia, solo habrá de llegarle como gracia ${ }^{29}$.

Desde tal perspectiva, la esperanza cristiana, en cuanto comporta para el hombre una salida de sí mismo, al confiar únicamente en la promesa divina y renunciar, por consiguiente, a todo cálculo cuantitativo que intramundanamente podría

${ }^{26}$ De acuerdo con el planteamiento de Alfaro, el futuro constituye para el hombre el horizonte de realización de sus aspiraciones más profundas que proyecta en el transcurso de su vida. Esto coloca a nuestro autor ante el tema de la esperanza y su relación con la interioridad humana. A propósito, se puede indicar lo siguiente: (1) La conciencia, la libertad, la historicidad y la temporalidad, entendidas como las dimensiones fundamentales de la existencia humana en su relación al mundo y a la humanidad constituyen la sede donde la esperanza manifiesta su presencia (Alfaro, "Las esperanzas intramundanas y la esperanza cristiana", 352). (2) La conciencia es la que otorga conocimiento experiencial, es decir, atemático, y certeza vivida: no refleja, en relación con la decisión de esperar. En efecto, la conciencia es la dimensión donde el hombre conoce, por experiencia vivida -no categorial- el amor de Dios para con él, experiencia que le permite captar lo fundamental de la promesa de Dios como base de su certeza -también vivida- de esperar tendiendo hacia la salvación futura (ibíd., 360). (3) El misterio del hombre, en cuanto espíritu finito, se revela por medio de la esperanza (ibíd., 352).

${ }_{27}$ Ídem, "La negación nihilista del sentido de la vida: Nietzsche y Sartre”, 107.

${ }^{28}$ Ídem, Esperanza cristiana y liberación del hombre, 41.

${ }^{29}$ Ibíd., 164; ídem, "Las esperanzas intramundanas y la esperanza cristiana”, 352-353; 164; ídem, "El hombre abierto a la revelación de Dios", 62; ídem, "Perspectivas para una teología sobre la fe", 112; ídem, "La plenitud de la revelación cristiana: su interpretación teológica”, 193-194; ídem, "El devenir histórico y su sentido", 269-270. Por cierto, la penultimidad propia de cada una de las metas logradas por el hombre en el mundo, que dan cuenta de la imposibilidad para él de una plenitud dentro del mundo (ídem, Esperanza cristiana y liberación del hombre, 18-19; ídem, "La cuestión del sentido y el sentido de la cuestión", 389) muestra que la esperanza es también esperante respecto a lo definitivamente último (ídem, "Escatología, hermenéutica y lenguaje”, 236), es decir, respecto a una plenitud suprahistórica que la humanidad solo podrá alcanzar como gracia absoluta recibida en la autodonación última de Dios (ídem, "Escatología, hermenéutica y lenguaje”, 238; ídem, “Esperanza marxista y esperanza cristiana”, 117). 
presentársele -tentando su frágil libertad- como garantía de salvación es "existencia en éxodo" "30, la cual, naturalmente, ha de llevar incorporado el servicio a los hombres.

En efecto, así lo plantea Alfaro: “...la esperanza cristiana no es el opio del consuelo o de la resignación fatalista, sino la exigencia del éxodo radical de sí mismo en el abandono audaz de la gracia de Dios y en el servicio de los hombres" ${ }^{31}$.

\section{La conciencia y la libertad, sede donde se fragua la cuestión de Dios como fundamento del ilimitado trascender del hombre y de su incondicional interpelación}

Para Alfaro, la cuestión de Dios emerge -se halla implícita- en las experiencias fundamentales que el hombre vive cuando asume y se sumerge en la cuestión constitutiva acerca de sí mismo. Esto quiere decir que el contenido mismo de la idea de Dios se manifiesta -está sugerido- en el proceso de reflexión antropológica tendiente a comprender la totalidad del sentido existencial ${ }^{32}$.

Ello se ve con cierta nitidez en la relación que el hombre establece con el devenir histórico de cara al futuro. Para Alfaro, "si el hombre no estuviera constitutivamente abierto al trascendente (si estuviera encerrado en su relación puramente inmanente al conjunto mundo-humanidad-historia), no podría ni siquiera buscar a Dios (ponerse la cuestión de Dios)" ${ }^{33}$.

Tal inmovilidad hacia Dios tendría su causa en la inexistencia de la subjetividad, en cuyo caso la humanidad se hubiera movido solo al interior del mundo, en un permanente proceso orientado hacia una plenitud inmanente, pues hubiese carecido de un núcleo ontológico que la capacitase para orientar la existencia hacia una realidad supratemporal, y mucho menos para acoger y responder a una eventual interpelación personal proveniente desde allá3 ${ }^{34}$. En esa hipotética situación no hubiese habido posibilidad alguna de que Dios emergiera como el hacia dónde último de la subjetividad humana ${ }^{35}$; sin embargo:

\footnotetext{
${ }^{30}$ Ídem, "Las esperanzas intramundanas y la esperanza cristiana”, 360. Al respecto véase también, ídem, Esperanza cristiana y liberación del hombre, 42-43; ídem, "El devenir histórico y su sentido”, 268.

${ }^{31}$ Ídem, Esperanza cristiana y liberación del hombre, 178; ídem, "Esperanza marxista y esperanza cristiana", 117-118.

32 Ídem, "La cuestión del sentido y el sentido de la cuestión", 400-403; ídem, "El hombre abierto a la revelación de Dios", 16; ídem, "Perspectivas para una teología sobre la fe", 111; ídem, "Epílogo", $272-273 ; 279$.

33 Ídem, "La cuestión del sentido y el sentido de la cuestión”, 402.

${ }^{34}$ Ídem, Esperanza cristiana y liberación del hombre, 164.

35 Ídem, “Epílogo”, 281-282.
} 
Una plenitud intrahistórica, definitiva e inmanente, de la historia [...] terminaría en un callejón sin salida: el desnivel entre la subjetividad humana y su objetivación en la transformación de la naturaleza quedaría radicalmente superado, y entonces la humanidad se encontraría irremediablemente encarcelada en la prisión que ella misma habría construido a lo largo de la historia: no podría ni esperar, ni descubrir, ni hacer nada, ni siquiera tener conciencia de sí misma. Suprimida la condición fundamental, que hace posible toda su relación al mundo, la humanidad sucumbiría por asfixia: su victoria final sería su derrota definitiva, su absorción en la naturaleza transformada, en la obra de sus manos. ${ }^{36}$

Dado que la existencia del hombre histórico y real no es así, Alfaro señalará -en coherencia con lo planteado en el punto anterior- que esa aspiración ilimitada constitutiva del hombre, tendiente a superar toda meta alcanzada, que pone en evidencia el insuperable desnivel existente entre ella y la incapacidad del hombre para alcanzar por sí mismo su consecución final, lejos de condenarlo a una existencia contradictoria y absurda, constituye "la condición ontológica indispensable de la acción libre del hombre" ${ }^{37}$.

Ahora bien, si se considera que esta condición ontológica -que impulsa a la libertad a través de sus diversas opciones, ilimitadamente hacia más allá de toda meta alcanzada-, se halla unida a otra dimensión ontológica de la libertad, la de estar incondicionalmente interpelada, entonces es posible concluir -a partir de lo señalado por el autor-que en ese trascender ilimitado y en esa interpelación incondicional se encuentra implícita la cuestión del hacia qué, la cuestión del incondicionado trascendente $^{38}$-la cuestión de Dios, en definitiva- como libertad absoluta-autofundante ${ }^{39}$.

Finalmente, respecto de este punto, Alfaro detectará que en la cuestión de Dios se manifiestan las mismas notas distintivas presentes en la cuestión del hombre:

- En primer lugar, del mismo modo como es el hombre quien se halla interpelado por la cuestión del sentido de su vida, dado su carácter apriórico -razón por la cual no es él quien le da movimiento a esta cuestión, sino más bien es él quien está movido por ella ${ }^{40}-$, así también es la cuestión de Dios la que lo interpela y mueve, en

36 Ídem, "Escatología, hermenéutica y lenguaje”, 237-238

${ }^{37}$ Ídem, "La negación nihilista del sentido de la vida: Nietzsche y Sartre", 94.

${ }^{38}$ En este punto, Alfaro muestra que su reflexión teológica emerge del diálogo con el pensamiento de Nietzsche (Alfaro, "La negación nihilista del sentido de la vida: Nietzsche y Sartre", 94).

39 Ídem, "Epílogo”, 283-284.

${ }^{40}$ Ídem, "La cuestión del sentido y el sentido de la cuestión”, 396; ídem, "El hombre abierto a la revelación de Dios", 16; ídem, "Perspectivas para una teología sobre la fe”, 111. 
virtud de lo cual Alfaro señala que "propiamente hablando, no sería el hombre el que busca a Dios, sino Dios el que vendría al encuentro del hombre” ${ }^{41}$.

- $\quad$ En segundo lugar, la cuestión de Dios, así como la cuestión del hombre, comporta una llamada total que integra, en forma indivisible, conocimiento y opción, problema y tarea, pregunta destinada a la inteligencia e interpelación ejercida a la libertad. De este modo, precisa el autor, ante la cuestión de Dios quedaría descartada una eventual actitud neutra, y se exige, en cambio, una disposición comprometida de la libertad ante ella ${ }^{42}$. En este sentido, tal disposición colocaría la libertad humana ante una decisión cuya opción -aceptación o rechazo de Dios- se erigiría como su actuación suprema, en la que ella, en cuanto libertad, se realizaría de la manera más libre ${ }^{43}$. - $\quad$ En tercer lugar, la respuesta a la cuestión de Dios habrá de ser -igual que la respuesta a la cuestión del hombre- de tipo mostrativo y no demostrativo: porque si, ante la cuestión del hombre, el sujeto se halla en presencia de su propio misterio, incapacitado para encontrar una respuesta desde su racionalidad meramente lógica ${ }^{44}$, ante la cuestión de Dios se halla en presencia del misterio por excelencia y, por ello, supremamente interpelado en su libertad por la llamada de aquel que lo cuestiona total y radicalmente ${ }^{45}$.

Habrá que decir, entonces, que la cuestión de Dios se fragua en el seno de las estructuras antropológicas previas -en la conciencia y en la libertad-, razón por la cual dicha cuestión pertenece a la precomprensión vivencial que el hombre tiene de sí mismo ${ }^{46}$, y desde ahí se manifiesta como respuesta necesaria a la cuestión de sí, hasta en su última instancia ${ }^{47}$.

${ }^{41}$ Ídem, "La cuestión del sentido y el sentido de la cuestión”, 402.

${ }^{42}$ Ibíd., 402; ídem, "La cuestión del hombre en su relación al mundo", 216-217.

43 Ídem, "La negación nihilista del sentido de la vida: Nietzsche y Sartre”, 99.

${ }^{44}$ El carácter mostrativo y no demostrativo de la cuestión del hombre y de la cuestión de Dios tiene, en el pensamiento de Alfaro, clara influencia proveniente por una parte de la filosofía kantiana, específicamente de la distinción entre razón teórica y razón práctica. Ciertamente, para Alfaro, la demostración estaría en relación con la razón teórica y la mostración con la razón práctica (Alfaro, "La cuestión del hombre y de Dios en la filosofía de I. Kant, L. Feuerbach y M. Heidegger”, 33). Por otra parte, también recibe influencia que proviene del pensamiento de Heidegger. Por cierto, el carácter no demostrativo tanto de la cuestión del hombre como de la cuestión de Dios se hallaría en la línea del rechazo a la metafísica occidental presente en la filosofía de este autor (Alfaro, "La cuestión del hombre y de Dios en la filosofía de I. Kant, L. Feuerbach y M. Heidegger", 71).

45 Ídem, “La cuestión del sentido y el sentido de la cuestión”, 402; ídem, “Epílogo”, 282-283.

${ }^{46}$ Ídem, "La cuestión del sentido y el sentido de la cuestión”, 402.

${ }^{47}$ Ibíd., 400; ídem, “Epílogo”, 280. 
Desvinculada de la cuestión del hombre, no podría darse la cuestión de Dios: si esta cuestión fuera meramente paralela a la cuestión del hombre, no insertada en la cuestión del sentido de la vida humana, no podría ser cuestión para nosotros, para mí: sería una cuestión de la que podría prescindir porque no tendría nada que ver con mi vida. ${ }^{48}$

\section{La muerte como la experiencia más radical de la negatividad de la subjetividad}

La negatividad de la subjetividad se hace presente en el hombre no solo como experiencia de no plena conciencia de sí mismo: ciertamente, tal negatividad alcanza su nivel más alto de expresión cuando erige la conciencia como el ámbito donde el hombre vive la experiencia significativa de la muerte ${ }^{49}$, de ser para ella ("ser-para-la-muerte") ${ }^{50}$. Para Alfaro, esta experiencia significativa de la muerte es vivida por el hombre en su interioridad, de dos maneras estrechamente relacionadas: como experiencia anticipada de ella y como experiencia de rebelión ante ella. Esta última, a su vez, conlleva implícitamente una experiencia de esperanza y otra de desafío para la libertad.

\section{La subjetividad, dimensión donde se anida}

la experiencia anticipada de la muerte

Según Alfaro, la experiencia anticipada de la propia muerte adquiere diversas maneras complementarias de expresión sintomática en la existencia concreta del hombre.

Por una parte, la simple acción del hombre relativa a pensar sobre la realidad de la muerte a causa de estar viviendo habitualmente junto a ella como inevitable, imprevisible, irreversible y enigmática ${ }^{51}$ "compañera-no-deseada e inseparable" ${ }^{2}$; o por otra parte, el hecho de estar viviendo cotidianamente la experiencia de dependiente necesidad respecto de los demás y de la naturaleza, como realidades que representan una amenaza para su vida por cuanto escapan a su total dominio $0^{53}$, pueden por separado o

${ }^{48}$ Ibíd., 280.

${ }_{49}$ Ídem, "La muerte y el sentido de la vida", 244; ídem, "El hombre abierto a la revelación de Dios", 39; ídem, "Las esperanzas intramundanas y la esperanza cristiana", 355; ídem, Hacia una teología del progreso humano, 47-48.

${ }^{50}$ Ídem, Esperanza cristiana y liberación del hombre, 20; ídem, "La cuestión del hombre y de Dios en la filosofía de I. Kant, L. Feuerbach y M. Heidegger”, 54.

${ }^{51}$ Ídem, "La muerte y el sentido de la vida”, 242-248; ídem, "El hombre abierto a la revelación de Dios”, 42.

52 Ibíd., 42; ídem, "La muerte y el sentido de la vida”, 247.

53 Ídem, "El hombre abierto a la revelación de Dios", 40-41; ídem, "La muerte y el sentido de la vida”, 246-247. 
conjuntamente constituirse en el contexto vital desde el cual emergen las experiencias de soledad radical $^{54}$, de temporalidad limitada ${ }^{55}$ (que se desenvuelve entre el tiempo preexistente a él y el tiempo que seguirá después del final de su vida) ${ }^{56}$, en definitiva, de inseguridad interna y de angustia permanente, como anticipo de su propia muerte ${ }^{57}$.

Ahora bien, este anticipo de la propia muerte representa para el hombre, además, una constante amenaza por la posibilidad de la nada, del no-ser definitivo ${ }^{58}$, de la aniquilación del ser conciencial de la persona que ella comporta, y con ello, de la destrucción total de las relaciones que el hombre establece con Dios, con los demás hombres y con el mundo 59 .

\begin{abstract}
${ }^{54} \mathrm{Al}$ respecto Alfaro señala que existe una "dimensión de la experiencia existencial que anuncia y anticipa la muerte: la experiencia de soledad, que hace de telón de fondo aun en los momentos más exaltantes de comunión interpersonal en la mutua donación del amor y de las autorrealizaciones más logradas. En lo más hondo de sí mismo, cada hombre está siempre solo, nunca plenamente integrado en la realidad de lo otro (mundo y personas), solo (aun respecto de sí mismo) en la nunca totalmente lograda identificación consigo mismo. Es una soledad de muerte, de vacío de vida, de vida minada anticipadamente por la muerte. El hombre muere solo, en la soledad suprema, previamente anunciada en la soledad honda que marca su vida" (Alfaro, "El hombre abierto a la revelación de Dios",41; ídem, "La muerte y el sentido de la vida”, 247). Esta soledad radical, asumida en profundidad -que no recurre a los otros ni al mundo pues sería una expresión de huida de sí mismo- como manifestación de aceptación anticipada de la muerte, entendida a modo de posibilidad suprema, la más propia e insuperable de la existencia, constituiría en el pensamiento de Heidegger -según la interpretación de Alfaro- una de las notas distintivas de una existencia humana auténtica (Alfaro, "La cuestión del hombre y de Dios en la filosofía de I. Kant, L. Feuerbach y M. Heidegger”, 55ss.).

${ }^{55}$ Ídem, "El hombre abierto a la revelación de Dios", 41; ídem, "La muerte y el sentido de la vida", 246-247.

${ }^{56}$ Estos límites tienen su fuente intelectual en A. Schopenhauer. Véase a Alfaro, "La muerte y el sentido de la vida", 248.
\end{abstract}

57 Ídem, Hacia una teología del progreso humano, 46-47; ídem, Esperanza cristiana y liberación del hombre, 20; ídem, "Foi et existence", 562-563; ídem, "Actitudes fundamentales de la existencia cristiana", 457; ídem, "Las esperanzas intramundanas y la esperanza cristiana", 355; ídem, "La cuestión del hombre y de Dios en la filosofía de I. Kant, L. Feuerbach y M. Heidegger”, 53-54.

${ }^{58}$ Ídem, Hacia una teología del progreso humano, 46-48; ídem, Esperanza cristiana y liberación del hombre, 20; 163; ídem, "El hombre abierto a la revelación de Dios", 42; ídem, "La muerte y el sentido de la vida", 249; ídem, "Foi et existence", 562-563; ídem, "La cuestión del hombre y de Dios en la filosofía de I. Kant, L. Feuerbach y M. Heidegger", 56.

${ }^{59}$ En relación con esto, Alfaro advierte acerca de la necesidad de no trivializar la muerte: "Cada hombre lleva escrito en lo más profundo de sí el destino a la muerte, que gravita sobre su existencia como una necesidad inevitable y una amenaza constante. La presencia interna de la muerte afecta al hombre de un modo tan eficaz como oculto; tiene lugar en el nivel más hondo del misterio del hombre y pesa de un modo decisivo en su actitud fundamental ante Dios, los hombres y el mundo" (Alfaro, Hacia una teología del progreso humano, 46-47). De ahí la necesidad de no trivializar la muerte, sumergiéndose en el activismo cotidiano del día a día, viviendo como si no hubiese que morir. Al trivializar la muerte -precisa Alfaro- se trivializa con ello también la vida, dado que "una existencia alienada de la muerte es paradójicamente una existencia alienada de sí misma. El intento de enterrar la muerte bajo el creciente cúmulo de las esperanzas intramundanas está de antemano condenado al fracaso: es inútil buscar 'seguros de vida' contra 
En efecto, el hombre -precisa Alfaro- activa la conciencia de sí mismo mediante las representaciones objetivas que surgen de las relaciones que establece con el mundo y con los demás hombres; de ahí que, si el evento de la muerte conlleva la posibilidad de supresión definitiva de dichas relaciones, tal supresión determina de manera inevitable la sensaciones de absurdidad ante la vida y de angustia, provocadas por las posibilidades de ser absorbido por la nada ${ }^{60}$, de hundirse en una extinción total en el absoluto no-ser de la autoluminosa interioridad, es decir, de la conciencia ${ }^{61}$. De manera más específica, todo ello comportaría además -según Alfaro- la aniquilación de la persona ${ }^{62}$, el despojo del $y o^{63}$, el "dejar de ser sí-mismo" ${ }^{64}$, la desvinculación total del sujeto respecto del mundo.

Por estas razones, la desvinculación del mundo y el aniquilamiento de la conciencia se presentan como experiencias reveladoras de una existencia humana amenazada permanentemente por la posibilidad de un "futuro no-más-vivir"

Lo señalado deja en evidencia que el anticipo de la muerte cuestiona radical e ineludiblemente, a su vez, el sentido de la vida humana ${ }^{66}$ en su totalidad, por cuanto

la seguridad de la muerte" (Alfaro, "Las esperanzas intramundanas y la esperanza cristiana", 354-355; ídem, Esperanza cristiana y liberación del hombre, 20; ídem, "La muerte y el sentido de la vida", 239-240). ${ }^{60}$ Ídem, Hacia una teologia del progreso humano, 47; ídem, Esperanza cristiana y liberación del hombre, 22; 163; ídem, "El hombre abierto a la revelación de Dios", 38; ídem, "La muerte y el sentido de la vida”, 252-254. Bajo este planteamiento de Alfaro subyace la antropología de J. P. Sartre. Véase a Alfaro, "La negación nihilista del sentido de la vida: Nietzsche y Sartre", 103-104; ídem, "El hombre abierto a la revelación de Dios", 44; ídem, "La muerte y el sentido de la vida”, 253.

${ }^{61}$ Ídem, Hacia una teología del progreso humano, 47-48; ídem, "Las esperanzas intramundanas y la esperanza cristiana”, 355 .

${ }^{62}$ Ídem, "El hombre abierto a la revelación de Dios", 42-43; ídem, "La muerte y el sentido de la vida", 248-252; ídem, "Epílogo”, 275.

${ }^{63}$ Alfaro reconoce en Unamuno el origen de esta afirmación: en efecto, el miedo "que la muerte suscita en el hombre es totalmente singular; es el temor de no-vivir-más, de no-ser-más-yo-mismo. Unamuno lo ha expresado con una frase breve y densa: 'me arrebatan mi yo"' (Alfaro, "El hombre abierto a la revelación de Dios", 42; ídem, "La muerte y el sentido de la vida", 250).

${ }^{64}$ Ibíd., 251; 247; ídem, "El hombre abierto a la revelación de Dios”, 43.

${ }^{65}$ Ídem, "La cuestión del sentido y el sentido de la cuestión", 390; ídem, "El hombre abierto a la revelación de Dios", 42.

66 Ídem, "La cuestión del sentido y el sentido de la cuestión", 390-391; ídem, "El hombre abierto a la revelación de Dios", 38; 42; ídem, "La muerte y el sentido de la vida", 239-240; 252. La evidencia existencial de un no existir por siempre revela que la existencia del hombre tiene un término final "que la marca intrínsecamente como no-fundada en sí misma. Aquí la muerte desenmascara despiadadamente la ilusión de todo progressus in infinitum: es un stop que hace imposible todo volver hacia atrás y todo seguir hacia adelante. Desde que cada hombre comienza a vivir, comienza a morir, comienza a acercarse al término final, la muerte, porque su vida está inexorablemente destinada a acabarse en la muerte. No es necesario mostrar que la muerte pone en cuestión el sentido de nuestra vida: ella se muestra por sí 
la muerte conllevaría la destrucción de la esencial proyección al futuro que tiene la vida y, por tanto, su no compleción ${ }^{67}$. Con ello otorga la posibilidad para que la vida se interrogue a sí misma a propósito de la muerte, lo que muestra a esta última como una cuestión dotada de sentido ${ }^{68}$.

Por eso -concluye Alfaro-, el hecho de no asumir la importancia que tiene la cuestión de la muerte, por una ilusoria y alienante pretensión de vivir como si no se fuera a morir, equivale a soslayar la autenticidad de la existencia humana ${ }^{69}$.

\section{La subjetividad, dimensión donde se fraguan las experiencias de rebelión ante la muerte, de esperanza y de desafío para la libertad respecto a una realidad autofundante}

\section{La esperanza y el deseo de vivir como manifestaciones de trascendencia, forjadoras de la actitud de rebelión}

A pesar de lo señalado en el punto anterior, Alfaro plantea que junto a la experiencia anticipada de la muerte estaría coexistiendo simultáneamente una actitud insubordinada ante la amenaza del no-ser -de la nada- que ella traería consigo, en virtud de lo cual se revela la identidad del hombre como espíritu y, por ello, su trascendencia respecto al mundo ${ }^{70}$.

De acuerdo con nuestro análisis estaría quedando de manifiesto que -para nuestro autor- el temor a la muerte como amenaza de aniquilación de la persona proviene de la conciencia que el hombre tiene de sí mismo ${ }^{71}$. Sin embargo, Alfaro señala que tal temor solo es posible porque en la conciencia habita también la esperanza radical

misma como cuestión inevitable, como la cuestión que más fuerte y radicalmente nos cuestiona. El enigma de la muerte hace de nuestra vida enigma, que nos interpela: '¿A dónde voy?’ Y '¿después qué?’: ‘¿En último término para qué vivir?’” (Alfaro, "La cuestión del sentido y el sentido de la cuestión”, 391; ídem, "La muerte y el sentido de la vida", 242).

${ }^{67}$ Respecto de la destrucción de la vida como proyecto, de su incompleción, véase a Alfaro, "El hombre abierto a la revelación de Dios", 38-39; ídem, "Libertad y verdad", 58-59; ídem, "La muerte y el sentido de la vida", 240; 256; ídem, "Epílogo", 275; 278; ídem, Esperanza cristiana y liberación del hombre, 20, cita 12; ídem, "La cuestión del sentido y el sentido de la cuestión", 391; ídem, "La cuestión del hombre y de Dios en la filosofía de I. Kant, L. Feuerbach y M. Heidegger”, 49; 51; 54; 64.

${ }^{68}$ Ídem, "La muerte y el sentido de la vida", 242.

${ }^{69}$ Ídem, Esperanza cristiana y liberación del hombre, 20; ídem, "El hombre abierto a la revelación de Dios", 38-39; ídem, "Las esperanzas intramundanas y la esperanza cristiana", 354-355; ídem, "La cuestión del hombre y de Dios en la filosofía de I. Kant, L. Feuerbach y M. Heidegger”, 56; ídem, "La muerte y el sentido de la vida", 239-240.

${ }^{70}$ Ídem, Hacia una teología del progreso humano, 48; 56; ídem, "Foi et existence”, 562.

${ }^{71}$ Ídem, "El hombre abierto a la revelación de Dios", 43; ídem, "La muerte y el sentido de la vida", 251. 
de seguir viviendo. Habita como dimensión originaria, previa al temor -como su supuesto $^{72}-$, lo cual indica que "donde no hay deseo, ni esperanza, no puede surgir el temor"73.

Esto significa que, sin perjuicio del sentimiento de temor seńalado, la esperanza, en su trascendencia respecto de todas las opciones intramundanas y en su apertura ilimitada hacia un más allá de todo logro alcanzado, no permite que la amenaza de la muerte se imponga a ella y la lleve a sucumbir ${ }^{74}$.

A partir de aquí se explica, para Alfaro, la mencionada actitud de rebelión e insubordinación como manifestación de no resignación ante la amenaza del destino fatal que comporta la muerte ${ }^{75} \mathrm{y}$, al mismo tiempo, la trascendencia del hombre respecto del mundo, trascendencia que muestra la existencia de la esperanza -anidada en la conciencia- como expresión de que dicho destino fatal no tendrá la última palabra para la humanidad.

Esto, según Alfaro, porque la conciencia, al llevar en sí misma la autoluminosa experiencia de su propio ser -donde reside la apertura metahistórica de la libertad ${ }^{76}$ como fundamento de su autotrascendencia hacia el futuro ${ }^{77}$-, no puede considerar a la negatividad, la nada, como su corolario definitivo, pues ello constituiría el triunfo del no $\operatorname{ser}^{78}$, del absurdo, del no sentido, del no más futuro; sería la constatación de que, en definitiva, la totalidad de las aspiraciones humanas, de sus decisiones y acciones, tendrían como soporte el fatal engańo de un espejismo; una constitutiva y originaria ilusión ubicada en lo más íntimo de su ser ${ }^{79}$, todo lo cual, ciertamente, dejaría la cuestión de Dios totalmente privada de significado ${ }^{80}$.

\footnotetext{
${ }^{72}$ En este sentido, Alfaro señala que "la dimensión originaria no es el temor, sino la esperanza-esperante; el temor de no vivir-más supone (como ontológicamente previo) el deseo radical de vivir, y por consiguiente el esperar radical" (Alfaro, "El hombre abierto a la revelación de Dios", 43; ídem, "La muerte y el sentido de la vida", 251.

${ }^{73}$ Ídem, "El hombre abierto a la revelación de Dios", 43; ídem, "La muerte y el sentido de la vida", 251.

${ }^{74}$ Ibíd., 251; 253; ídem, "El hombre abierto a la revelación de Dios”, 45.

${ }^{75}$ Ídem, Hacia una teología del progreso humano, 47-48; ídem, Esperanza cristiana y liberación del hombre, 21; ídem, "Las esperanzas intramundanas y la esperanza cristiana", 355.

${ }^{76}$ Ídem, "Perspectivas para una teología sobre la fe”, 112.

77 Ídem, "El hombre abierto a la revelación de Dios", 24; ídem, "La cuestión del hombre en su relación al mundo", 207-208.

${ }^{78}$ Ídem, "Las esperanzas intramundanas y la esperanza cristiana”, 355; ídem, "Libertad y verdad”, 59; ídem, "Escatología, hermenéutica y lenguaje", 236-237; ídem, "El hombre abierto a la revelación de Dios", 44-45; ídem, "La muerte y el sentido de la vida", 253; ídem, "Epílogo", 275; ídem, Hacia una teología del progreso humano, 53; ídem, Esperanza cristiana y liberación del hombre, 22.

${ }^{79}$ Ibíd., 21-22; ídem, "El hombre abierto a la revelación de Dios", 44; ídem, "La muerte y el sentido de la vida", 252-253; ídem, "Epílogo", 275-276.

${ }^{80}$ Ibíd., 281.
} 


\section{El desafio de la libertad ante la frontera de trascendencia que comporta la experiencia de la muerte}

La reflexión acerca de la muerte ha mostrado "que la vida humana es esperanza trascendente de sentido, esperar-esperante ilimitado que va más allá de la muerte" ${ }^{81}$; que esta, entendida como aniquilación de la persona, "estaría en contradicción con la estructura ontológica del esperar radical y privaría de sentido la totalidad de la vida" ${ }^{2}$. De ahí la actitud de no resignación e insubordinación que emerge de la subjetividad humana.

A partir de ello Alfaro entiende que la experiencia humana de cercanía cotidiana con la muerte se erige como dilema de sentido existencial que tendría la característica de ser frontera de trascendencia. Esta colocaría permanentemente la libertad del hombre en situación límite ${ }^{83}$, ante la cual el ser humano quedaría de cara a dos opciones:

- Una existencia abierta, valiente y confiada a la esperanza de un porvenir trascendente -como llamado interior (desde la conciencia) ${ }^{84}$ que la misma esperanza realiza a la libertad-, que reconoce a Dios como valor absoluto y su sentido último, en virtud de lo cual centra su opción fundamental en él ${ }^{85}$.

- Una existencia autónoma, confinada a las meras circunstancias intramundanas ${ }^{86}$; pero en tal caso:

La aceptación resignada o heroica de la muerte, como naufragio fatal y total de la existencia, es en el fondo la más radical desesperación. El hombre se niega entonces a escuchar la llamada más íntima de su conciencia; cierra los ojos a la luz inextinguible de su propia interioridad, a la luz que es él mismo. ${ }^{87}$

Lo señalado permite al autor destacar el carácter de cuestión significativa que posee la esperanza última, más allá de la muerte ${ }^{88}$. Dicha esperanza, si bien corresponde

${ }^{81}$ Ídem, "El hombre abierto a la revelación de Dios", 45; ídem, "La muerte y el sentido de la vida", 254.

${ }^{82}$ Ídem, "El hombre abierto a la revelación de Dios", 45; ídem, "La muerte y el sentido de la vida", 253-254.

83 Ídem, Esperanza cristiana y liberación del hombre, 22-23; ídem, "Las esperanzas intramundanas y la esperanza cristiana”, 356; ídem, "Escatología, hermenéutica y lenguaje”, 236; ídem, "El hombre abierto a la revelación de Dios", 45; ídem, "La muerte y el sentido de la vida”, 253-254.

${ }^{84}$ Ídem, "Foi et existence", 562.

85 Ídem, "Actitudes fundamentales de la existencia cristiana”, 457-458; ídem, “Epílogo”, 375.

${ }^{86}$ Ídem, "Las esperanzas intramundanas y la esperanza cristiana", 355-356; ídem, "Tecnopolis e cristianesimo", 536; ídem, "Actitudes fundamentales de la existencia cristiana", 457-458; ídem, "Libertad y verdad", 59; ídem, "El hombre abierto a la revelación de Dios", 39; 43; 45; ídem, "La muerte y el sentido de la vida", 241; 252; 254.

87 Ídem, Hacia una teología del progreso humano, 48; ídem, Esperanza cristiana y liberación del hombre, 22-23; ídem "Libertad y verdad", 59.

${ }^{88}$ Ídem, "El hombre abierto a la revelación de Dios", 45; ídem, "La muerte y el sentido de la vida", 254; ídem, "El devenir histórico y su sentido", 268-269. 
a una dimensión constitutiva del hombre, no podría tener su fundamento en él, ni en ninguna realidad al interior del mundo o de la historia, pues la muerte traería consigo, precisamente, la ruptura de la relación que el hombre establece con el mundo y con la historia ${ }^{89}$. En efecto, si el sentido último de la vida se revela como esperar esperante trascendente, la muerte

...revela que esta esperanza constitutiva del hombre no puede estar fundada sino en una realidad trascendente de la que el hombre no puede disponer de ningún modo; puede solamente confiarse y abandonarse a ella en la actitud personal suprema de la esperanza, en la actitud de la invocación: para designar esta realidad trascendente personal, el lenguaje humano ha reservado un nombre propio: Dios. ${ }^{90}$

Se pone así en evidencia, a modo de conocimiento mostrativo - no demostrativo- ${ }^{91}$, que la cuestión y la afirmación de Dios como esperanza última arranca de la cuestión de la muerte en cuanto lugar privilegiado de la cuestión del hombre.

De esta manera - dice Alfaro- es en la conciencia donde se manifiesta la paradoja de la existencia del hombre como espíritu finito, en cuanto en ella resuena la convergencia de la finitud mortal y la ilimitada aspiración espiritual humana. Esta convergencia paradójica constituye el misterio fundamental del hombre, en el que este halla su orientación al misterio propio de Dios, quien se manifiesta como salvación de la amenaza de absurdo que comporta el desaparecimiento de su conciencia por la muerte ${ }^{92}$.

\section{La experiencia humana de no existir desde siempre (como existencia no fundada en si misma, como evento), y la apertura hacia una realidad autofundante y trascendente}

El cuestionamiento del sentido de la existencia humana se manifiesta en la experiencia de no existir para siempre-la muerte-, y también en la de no existir desde siempre, ambas consideradas como experiencias de la negatividad de la subjetividad ${ }^{93}$.

${ }^{89}$ Ídem, "El hombre abierto a la revelación de Dios", 45; ídem, "La muerte y el sentido de la vida”, 254.

90 Ídem, "El hombre abierto a la revelación de Dios", 45; ídem, "La muerte y el sentido de la vida", 254; ídem, "Epílogo", 276; 282-283; 285.

${ }^{91}$ Ídem, "La cuestión del sentido y el sentido de la cuestión", 402; ídem, "El hombre abierto a la revelación de Dios", 16-17; ídem, "La cuestión del hombre en su relación al mundo", 216-217; ídem, "Epílogo", 278-279.

92 Ídem, "Foi et existence", 562-563.

${ }_{93}^{3}$ Ídem, “La cuestión del sentido y el sentido de la cuestión”, 389-390; 393. 
Respecto de la segunda experiencia, el hombre la descubre cuando constata que su existencia en el mundo se realiza en condición de arrojado, es decir, como no venido a él por sí mismo, sin posibilidad alguna de haber elegido tal existencia ${ }^{94}$.

Para Alfaro, esta experiencia de dependencia constitutiva del hombre respecto del origen y continuidad de su existencia -que lo definiría como "evento, 'venido de" ${ }_{95}$ le impone, obviamente, la pregunta relativa al origen y al por qué de dicha existencia ${ }^{96}$.

Ciertamente, verificado como innegable el hecho de su existencia en el mundo y que ella tiene su origen fuera de sí -no en sí mismo-, le surge al hombre la necesidad de plantearse la cuestión relativa a un fundamento originario autofundante-trascendente, que no solo se presente como fundamento de sentido del origen de su existencia, sino que además la mantenga en él.

Supuesto esto, Alfaro pone en evidencia la incompatibilidad existente entre este fundamento autotrascendente con la hipótesis de un regressus in infinitum:

El sentido de la cuestión del fundamento originario apunta hacia un fundamento autofundante, es decir, no fundado sino en sí mismo, y que por consiguiente no esté originado en otro. Ciertamente es posible pensar (o al menos imaginar) un regressus in infinitum, es decir, una serie creciente y sin nunca término final de fundamentos intermedios y por consiguiente no-autofundantes, porque si por hipótesis ninguno de los fundamentos de la serie fuera último, tampoco ninguno de ellos podría ser autofundante. Y si ninguno de los fundamentos intermedios de esa serie fuera autofundante, la serie misma (por más que se la suponga nunca terminada), permanecerá siempre e inevitablemente carente de fundamentación ontológica, suspendida en el vacío. Aparece así que el mismo pensamiento, que puede crear la representación de una serie ilimitada de fundamentos intermedios (cada uno depende del otro y por consiguiente todos y cada uno son originados), trasciende su propia creación, al darse cuenta de que, por más que crezca ilimitadamente la serie de fundamentos noautofundantes, quedará siempre intacta la necesidad de una fundamentación no ya intermedia, sino autofundante y por eso fundante de toda serie posible de fundamentaciones no-autofundantes. El regressus in infinitum se revela pues como insuficiente para la comprensión del sentido de la cuestión del hombre en el "por qué" de la existencia humana, como no-fundada en sí misma, y por eso necesitada de un fundamento, en última instancia, autofundante. Toda serie ilimitada de fundamentos meramente intermedios remite por sí misma a un fundamento, que está más allá y fuera de ella. ${ }^{97}$

\footnotetext{
${ }^{94}$ Ibíd., 390; ídem, "El hombre abierto a la revelación de Dios", 13; 22; ídem, "La cuestión del hombre y de Dios en la filosofía de I. Kant, L. Feuerbach y M. Heidegger", 51.

${ }^{95}$ Ídem, "El hombre abierto a la revelación de Dios", 22.

${ }^{9}$ Ídem, "La cuestión del sentido y el sentido de la cuestión”, 390; ídem, "El hombre abierto a la revelación de Dios", 13; 22; ídem, "Epílogo", 277.

${ }^{97}$ Ídem, “La cuestión del sentido y el sentido de la cuestión”, 390-391; 392.
} 


\section{Conclusión}

Hay dos aspectos del planteamiento de Alfaro presentes en este artículo que deseamos relevar, pues consideramos que en cada uno habría elementos teóricos para profundizar en algunos planteamientos que ha realizado el papa Francisco respecto de la situación de la humanidad en el contexto actual, y de la necesidad de abrirse a nuevos lenguajes para abordarla.

El primer aspecto es el relativo a la negatividad de la subjetividad expresada mediante la amenaza de fracaso existencial que comportan las experiencias cotidianas de la vida, de la convivencia, pero especialmente de la muerte.

El segundo aspecto es el relativo a su antigua preocupación por la búsqueda de instrumentos hermenéuticos de carácter personalista, centrados en la subjetividad (afines a la mostración) para abordar dichas experiencias desde la teología, en lugar de instrumentos esencialistas, más afines a la demostración.

Como puede apreciarse, ambos aspectos coinciden en la subjetividad: el primero pone de relieve la vulnerabilidad de la subjetividad, y el segundo coloca esta como criterio interpretativo de la realidad.

Ahora bien, estos planteamientos de Alfaro, que tienen su ambiente de desarrollo en la época de posguerra europea, muestran, no obstante, una vigencia que otorga sustento teórico para penetrar en las mismas temáticas antropológicas que afectan a América Latina y que el actual pontífice ha puesto de relieve.

En efecto, para Alfaro la reflexión acerca de la vulnerabilidad de la subjetividad, como amenaza de fracaso existencial y como experiencia de muerte, si bien tiene una fuerte influencia de representantes emblemáticos del ateísmo existencial contemporáneo, también está relacionada con estructuras sociales que reducen el devenir histórico a un nivel puramente inmanente, constituyéndose en fuentes de pecado e induciendo a la humanidad a la negación de Dios.

Esta postura que de acuerdo al contexto es una crítica a la reducción marxista de la historia encontrará un complemento de mayor amplitud cuando Alfaro, en la década de los ochenta, señale que lo que caracteriza la situación de América Latina, desde una perspectiva religiosa, económica, social y política, es el "contraste estremecedor entre la profesión de la fe cristiana y la opresión (a todos los niveles) de minorías privilegiadas sobre las grandes masas de la población: contraste enorme entre la profesión y la práctica de la fe" ${ }^{98}$. Sobre lo mismo agregará:

No es casual que la teología de la liberación haya nacido en y de este contexto histórico: su origen profundo está en la sacudida de la conciencia cristiana ante el

${ }^{98}$ Ídem, “En torno a la teología de la liberación”, 163. 
escándalo de un cristianismo confesional encarnado en estructuras de opresión. Que por fin la teología se haya dado cuenta de este escándalo radicalmente anticristiano es un hecho altamente positivo, que está llamado a dar un viraje decisivo a la tarea teológica del futuro a nivel mundial. Se puede esperar que la teología no se volverá atrás hacia la indiferencia conformista ante el gran pecado de la opresión del hombre por el hombre, del cristiano por el cristiano. ${ }^{99}$

Tales temáticas, desarrolladas ampliamente por la teología latinoamericana y presentes también en importantes documentos del Celam -donde en mayor o menor medida la economía de planificación marxista como la economía libre de mercado aparecen relacionadas con estructuras de opresión que socavan la dignidad humana ${ }^{100}$ tienen clara continuidad en el discurso del papa Francisco, más centrado ciertamente en los efectos devastadores que provoca en la subjetividad de las personas la mentalidad mercado-centrista que se ha instalado a nivel global ${ }^{101}$.

Ahora bien, lo que llama nuestra atención no es precisamente la condición de vulnerabilidad de la subjetividad, sino la relación que hacen, tanto Alfaro como Francisco, de esta condición con el desafío que comporta la renovación de la reflexión acerca del concepto de persona, de racionalidad y de lenguaje. Para ambos, la persona no es el corolario del proceso evolutivo de la materia, entendida como supuesto natural para ser llamado a una relación con Dios; más bien, la persona, como sujeto inédito, consciente y libre, ha de suponer en su origen una intervención directa de Dios en el proceso evolutivo predecible del universo material que inaugura una relación personal de sujeto a sujeto (de tú a tú, de persona a persona) entre Dios y el hombre y por él con el mundo ${ }^{102}$ por medio de la conciencia y la libertad, entendida en su conjunto como la dimensión cualitativa de lo humano.

Por tanto, el ámbito donde se suscita dicha relación no podría radicar en la razón intelectual o lógica, pues esta es parte del proceso evolutivo de causas y efectos,

\footnotetext{
${ }^{99}$ Ibíd.

${ }^{100}$ Celam, II Conferencia General del Episcopado Latinoamericano. Documento de Medellín. Conclusiones. La Iglesia en la actual transformación de América Latina a la luz del Concilio: Promoción humana, I. Justicia 10; ídem, III Conferencia General del Episcopado Latinoamericano. La Evangelización en el presente y en el futuro de América Latina. Documento de Puebla 47-50; ídem, IV Conferencia General del Episcopado Latinoamericano. Santo Domingo. Nueva Evangelización; Promoción Humana; Cultura Cristiana; Jesucristo ayer, hoy y siempre 167; 199; ídem, V Conferencia General del Episcopado Latinoamericano y del Caribe. Discípulos y misioneros de Jesucristo para que nuestros pueblos en él tengan vida. Aparecida. Documento conclusivo 45.

${ }^{101}$ Francisco, Exhortación apostólica "Evangelii gaudium" 52-60; 202; ídem, Carta encíclica "Laudato si"” 56; 109; 123; 190; 195; 203; 215; ídem, Exhortación apostólica "Amoris latitia” 201.

102 Ídem, Carta encíclica "Laudato si”" 81; 65; Alfaro, "El hombre abierto a la revelación de Dios", 30; ídem, "La cuestión del hombre en su relación al mundo", 216.
} 
inherente a la naturaleza objetiva presente también en los animales infrahumanos. Aislada de la dimensión cualitativa de lo humano, se erigiría como aquella racionalidad instrumental "que solo aporta a un análisis estático de la realidad en función de necesidades actuales" 103 , al hacerse "presente tanto cuando quien asigna los recursos es el mercado como cuando lo hace un Estado planificador" ${ }^{104}$.

Esto significa que tal racionalidad ha constituido la base de sistemas positivistas, fundamentalistas e ideológicos, generadores de injusticias sociales que excluyen a los sujetos, ya sea por la represión de las libertades individuales en pos de la igualdad, ya sea por la fragmentación social que ha traído consigo la aplicación de políticas neoliberales mercadocentristas, causante esta última -entre otras cosas- de "tristeza individualista" ${ }^{105}$ e inequidad ${ }^{106}$.

Sin embargo, según nuestro parecer han existido otros tipos de fundamentalismos que han tenido como base la racionalidad lógica instrumental. Mencionemos dos:

- Por una parte, el positivismo científico que consideró como único criterio de verdad la verificación empírica y que, como tal, fue determinante en el progreso de la historia, mostró su lado oscuro en las dos guerras mundiales del siglo pasado. Aquí esta racionalidad fue puesta al servicio de la creación de elementos de destrucción masiva con los efectos conocidos por todos, lo que daría origen al existencialismo trágico y absurdo expresado en la literatura y la filosofía de mediados del siglo pasado, que interpelaría a la teología a reorientar su lenguaje, como queda de manifiesto en Alfaro.

- Por otra parte, el positivismo teológico doctrinal, hecho suyo por el cristianismo católico, decantó en fundamentalismo de la mano de una racionalidad lógica instrumental que definió objetivamente lo que había que creer y la voluntad de Dios en materia de conducta humana. Quienes no asumían esto en el pasado eran catalogados como infieles o herejes con las consecuencias violentas ya conocidas. Sin embargo, pareciera ser que este tipo de racionalidad mantendría todavía su vigencia, pues estaría en la base de estructuras eclesiales rígidas centradas en el control mediante el uso de poder (no necesariamente de autoridad), generadoras de modelos pastorales basados en el temor y de actitudes de abuso sexual y de conciencia.

Estos fundamentalismos, portadores de estructuras de violencia y de deterioro

\footnotetext{
${ }^{103}$ Francisco, Carta encíclica "Laudato si" 195; 115; 199.

${ }^{104}$ Ibíd. 195.

105 Ídem, Exhortación apostólica "Evangelii gaudium" 2; 63; 67; 208.

${ }^{106}$ Ibíd. 52; 53; 59; 60; 202; ídem, Carta encíclica "Laudato si”" 48-52; 90; 158.
} 
del bienestar subjetivo de las personas, estarían asociados a un tipo de racionalidad (instrumental, lógica, intelectual) que tendría sus raíces en la definición que Boecio hace de persona: substancia individual de naturaleza racional.

A base de tal racionalidad se habría establecido un enfoque positivista respecto de la realidad, donde la pregunta por su funcionamiento emergía como la relevante y el conocimiento adquirido a partir de ella y de su respuesta habría tenido el privilegio de ser considerada como la verdad (positivismo científico tecnológico; positivismo ideológico social; positivismo religioso doctrinal), con un lenguaje afín a ese tipo de verdad que a menudo excluyó otro tipo de acercamientos a la realidad, lo que habría comportado altos niveles de fundamentalismo intolerante y violento.

El conocimiento adquirido surgía (y lo sigue haciendo) a base de una relación instrumental-funcional con la realidad, incluidos los otros y Dios, cuya verificación, respecto de sus respectivas verdades, quedaba sustentada mediante la demostración empírica o lógica. En ese sentido, el misterio del hombre y el misterio de Dios eran reducidos a problemas y soluciones que quedaban encapsulados en un lenguaje destinado a la información instruccional, pero que no interpelaba hacia el encuentro con la dimensión profunda que posee el mundo, los otros y el otro.

Desde esta perspectiva queda de manifiesto el valor significativo del mensaje de Francisco, quien -en la línea de la Conferencia de Aparecida ${ }^{107}$ y apoyado en las enseñanzas de Juan XXIII y de Juan Pablo II- señala lo siguiente respecto de la necesidad de abrirse a nuevos lenguajes:

Al mismo tiempo, los enormes y veloces cambios culturales requieren que prestemos una constante atención para intentar expresar las verdades de siempre en un lenguaje que permita advertir su permanente novedad. Pues en el depósito de la doctrina cristiana "una cosa es la substancia [...] y otra la manera de formular su expresión". A veces, escuchando un lenguaje completamente ortodoxo, lo que los fieles reciben, debido al lenguaje que ellos utilizan y comprenden, es algo que no responde al verdadero Evangelio de Jesucristo. Con la santa intención de comunicarles la verdad sobre Dios y sobre el ser humano, en algunas ocasiones les damos un falso dios o un ideal humano que no es verdaderamente cristiano. De ese modo, somos fieles a una formulación, pero no entregamos la substancia. Ése es el riesgo más grave. Recordemos que "la expresión de la verdad puede ser multiforme, y la renovación de las formas de

${ }^{107}$ Celam, V Conferencia General del Episcopado Latinoamericano y del Caribe. Discipulos y misioneros de Jesucristo para que nuestros pueblos en él tengan vida. Aparecida. Documento conclusivo 55; 100, d; 341; $480 ; 517, \mathrm{~d}$. 
expresión se hace necesaria para transmitir al hombre de hoy el mensaje evangélico en su inmutable significado". ${ }^{108}$

Tal significado cobra evidencia cuando en la tarea de transmitir la Palabra revelada esta es puesta en conexión con la salvación, es decir, con el acontecimiento del encuentro con el amor de Dios, con su persona, y no con la información de ideas abstractas y repetidas ${ }^{109}$. Este desafío teológico que ya resaltaba Alfaro, de cara a la situación de vulnerabilidad existencial en la que se halla el hombre en el mundo, sigue vigente, de acuerdo con lo indicado en la Conferencia de Aparecida ${ }^{110}$ y en las enseñanzas del papa Francisco ${ }^{111}$.

\section{Referencias}

Ábrigo, Carlos. "El origen divino de la subjetividad en la reflexión teológica de Juan Alfaro. Las repercusiones en el hombre y las tensiones intelectuales del autor presentes en este proceso". Teología y vida 56/1 (2015): 95-124.

Alfaro, Juan. "Actitudes fundamentales de la existencia cristiana”. En Cristología y antropologia: temas teológicos actuales, por J. Alfaro, 413-476. Madrid: Cristiandad, 1973.

. "Cristo glorioso, revelador del Padre". Gregorianum 39 (1958): 222-270.

. "El devenir histórico y su sentido". En De la cuestión del hombre a la cuestión de Dios, por J. Alfaro, 255-270. Salamanca: Sígueme, 1989.

. "El hombre abierto a la revelación de Dios". En Revelación cristiana, fe y teología, por J. Alfaro, 13-64. Salamanca: Sígueme, 1994.

- "En torno a la teología de la liberación". En Revelación cristiana, fe y teología, por J. Alfaro, 161-174. Salamanca: Sígueme, 1994.

- "Epílogo". En De la cuestión del hombre a la cuestión de Dios, por J. Alfaro, 271-286. Salamanca: Sígueme, 1989.

${ }^{108}$ Francisco, Exhortación apostólica "Evangelii gaudium" 41; 11;22; 27; 35; 42; 73; 158; 167; 232; ídem, Carta encíclica "Laudato si" 11; 63; 66; 199.

${ }^{109}$ Ídem, Exhortación apostólica "Evangelii gaudium" 7-8; véase también a Alfaro "La fe como entrega personal del hombre a Dios y como aceptación del mensaje cristiano", 56-69.

${ }^{110}$ Celam, V Conferencia General del Episcopado Latinoamericano y del Caribe. Discipulos y misioneros de Jesucristo para que nuestros pueblos en él tengan vida. Aparecida. Documento conclusivo 341.

${ }^{111}$ Francisco, Exhortación apostólica "Evangelii gaudium" 40; 133; 147; ídem, Carta encíclica "Laudato si”"17; ídem, Exhortación apostólica "Amoris latitia" 36. 
. "Escatología, hermenéutica y lenguaje". En revelación cristiana, fe y teología, por J. Alfaro, 175-186. Salamanca: Sígueme, 1994.

. Esperanza cristiana y liberación del hombre. Barcelona: Herder, 1972.

. "Esperanza marxista y esperanza cristiana”. En Antropología y teología, por $\mathrm{H}$. Santiago, 85-123. Madrid: Consejo Superior de Investigaciones Científicas, 1978.

. "Foi et existence". Nouvelle Revue Theologische Zeitschrift 90 (1968): 561-580.

. Hacia una teología del progreso humano. Barcelona: Herder, 1974.

. "La antropología de Karl Marx". En De la cuestión del hombre a la cuestión de Dios, por J. Alfaro, 157-179. Salamanca: Sígueme, 1989.

. "La cuestión del hombre en su relación al mundo". En De la cuestión del hombre a la cuestión de Dios, por J. Alfaro, 201-217. Salamanca: Sígueme 1989. - "La cuestión del hombre y de Dios en la filosofía de I. Kant, L. Feuerbach y M. Heidegger". En De la cuestión del hombre a la cuestión de Dios, por J. Alfaro, 28-78. Salamanca: Sígueme, 1989.

. "La cuestión del sentido y el sentido de la cuestión”. Gregorianum 66 (1985): 387-403.

. "La dimensión trascendental en el conocimiento humano de Dios según Santo Tomás”. Gregorianum 55 (1974): 639-675.

. "La fe como entrega personal del hombre a Dios y como aceptación del mensaje cristiano". Concilium 21 (1967): 56-69

. "La muerte y el sentido de la vida". En De la cuestión del hombre a la cuestión de Dios, por J. Alfaro, 239-254. Salamanca: Sígueme, 1989.

- "La negación nihilista del sentido de la vida: Nietzsche y Sartre". En De la cuestión del hombre a la cuestión de Dios, por J. Alfaro, 79-108. Salamanca: Sígueme, 1989.

. "La plenitud de la revelación cristiana: su interpretación teológica". En Revelación cristiana, fe y teología, por J. Alfaro, 187-197. Salamanca: Sígueme, 1994. . "Las esperanzas intramundanas y la esperanza cristiana”. Concilium 59 (1970): 352-363.

- "Libertad y verdad". En Problemas de la Iglesia de hoy, por B. M. Aheim, 53-66. Madrid: Biblioteca de Autores Cristianos, 1975. 
. "Persona y gracia”. Gregorianum 41 (1960): 5-29.

. "Perspectivas para una teología sobre la fe". En Revelación cristiana, fe y teología, por J. Alfaro, 109-122. Salamanca: Sígueme, 1994.

. “Tecnopolis e cristianesimo”. La civiltà cattolica 2856 (1969): 533-548.

. "Trascendencia e inmanencia de lo sobrenatural". Gregorianum 38 (1957): $5-50$.

Celam. II Conferencia General del Episcopado Latinoamericano. Documento de Medellin. Conclusiones. La Iglesia en la actual transformación de América Latina a la luz del Concilio. Bogotá: Paulinas, 1968.

. III Conferencia General del Episcopado Latinoamericano. La Evangelización en el presente y en el futuro de América Latina. Documento de Puebla. Bogotá: Consejo Episcopal Latinoamericano, 1978.

. IV Conferencia General del Episcopado Latinoamericano. Santo Domingo. Nueva evangelización; Promoción humana; Cultura cristiana; Jesucristo ayer, hoy y siempre. Bogotá: Consejo Episcopal Latinoamericano, 1992.

. V Conferencia General del Episcopado Latinoamericano y del Caribe. Discipulos $y$ misioneros de Jesucristo para que nuestros pueblos en él tengan vida. Aparecida. Documento conclusivo. Bogotá: Consejo Episcopal Latinoamericano, 2007.

Francisco. Carta encíclica "Laudato si”. Santiago: PUC, 2015.

. Exhortación apostólica "Amoris laetitia". Santiago: PUC, 2016.

. Exhortación apostólica "Evangelii gaudium". Santiago: PUC, 2013. 